\title{
Roles of China's Government in Addressing Global Warming
}

\author{
Yuan Fang \\ School of Public Management (SPM), Yunnan University of Finance and Economics, P. R. China \\ (yuanfang6662783@126.com)
}

\begin{abstract}
Global warming has seriously affected the survival of mankind and the sustainable development of society. All countries in the world have taken measures to deal with the problem, and formed a series of effective international cooperation mechanism. China's government actively respond to global warming, and participate and cooperate as a developing country. China's government established the national climate change countermeasures coordination mechanism. Furthermore, according to the national strategy of sustainable development requirements, China's government has adopted a series of related policies and measures to deal with climate change. Targets for reducing carbon emissions are very arduous and long-term. The achievement of this goal and environmental protection and economic interests of the organization are a paradox. In the process of reducing carbon emissions and addressing climate warming, China's government needs to further enhance the ability of service, to strengthen the rule of law, to strengthen the sense of responsibility, and to improve work efficiency. China's government is actively playing planning, guiding and participatory role, in order to control global warming.
\end{abstract}

Keywords: Global warming, Government, Role

\section{Introduction}

Climate is the basic conditions for all life on earth. Climate is an important part that human social development depends on. Any climate change will have a significant impact on natural ecosystems and human economic and social life. In the past 100 years, the global climate is undergoing a significant change with warming. The United Nations Intergovernmental Panel on Climate Change (IPCC) has evaluated the global climate for four times respectively in 1990, 1995, 2001 and 2007.The fourth assessment report shows that global temperatures rise was 0.74 in twentieth Century. Global warming has seriously affected the survival of mankind and the sustainable development of society.

\section{The Present situations of the Global Warming}

From the perspective of natural science, factors causing climate warming can be divided into natural climate fluctuations and human activities. The rise of temperature is proportional to the concentrations of the greenhouse gases which take $\mathrm{CO}_{2}$ as the principal thing. Throughout human history of productivity, we can see that, with the development of society and the progress of science and technology, the request of nature and human destruction gradually upgrade. On the one hand, the rapid growth of population consumes a large number of non-renewable resources, resulting in the shortage of resources, destruction of biodiversity and global environmental pollution; on the other hand, the energy resources of coal, petroleum which are necessary for human production. As the main driving force of social and economic development, it produces large amounts of greenhouse gases in the mining and burning process.

It is an indisputable fact that $\mathrm{CO}_{2}$ from human activities caused climate warming. Climate warming leads to rising ocean temperatures. Polar ice and snow melt part and sea level continues to rise. In the coastal areas and the cities there will be a large number of homeless refugees. Due to climate warming, the climate is becoming abnormal in some areas. Extreme weather events such as high temperature, flood, and drought occur frequently. The sustainable development of agriculture is directly affected and human health is threatened.

It is clear that climate warming has had a serious impact on human survival and sustainable development of society. The grim reality is constantly sounded the alarm to the world. 


\section{Measures and Mechanisms of Countries Responding to Global Warming}

In twenty-first Centuries as the most important and the most challenging global issue, climate warming has been upgraded from a natural environment problem to the comprehensive problems covering politics, economy, law, and national security. If global warming is not effectively controlled, in the foreseeable future, the earth will be faced with a series of disasters, serious and unavoidable consequences may be caused eventually. To cope with the challenges, countries around the world are taking actions and formulating a series of policies about energy security and sustainable development. Through the implementation of adapting to the effects of climate change and reducing greenhouse gas emissions, the rate and magnitude of climate change can be reduced. However, $\mathrm{CO}_{2}$ as a Global Public Bads, its emissions will not cause a region or a country's pollution, but because of the accumulation in the atmosphere, it can cause a global temperature rise. Therefore, it can not be truly effective that $\mathrm{CO}_{2}$ emission reduction solely rely on a country or several countries carried out within the framework of the emission reduction measures. For the common interests of all countries to protect human beings, all countries in the world should carry out extensive cooperation in global.

In order to seek the effective measures to control global warming, the United Nations established the INCD in 1990 December, devoted to develop international convention on the control of global warming. Since then, climate warming and $\mathrm{CO}_{2}$ emission reduction are paid more and more close attention by the countries of the world. In 1992 June, United Nations Framework Convention on Climate Change established the basic principles of human response to climate change and long-term goal of stabilizing greenhouse gas concentrations. The Kyoto Protocol formulated In 1997 December provides quantitative emission reduction obligations, and establishes three major emission reduction mechanism based on the market. In 2005 November Montreal conference from the point of law ensures that the " Kyoto Protocol " starts running. " United Nations Framework Convention on Climate Change " and the " Kyoto Protocol " established the mechanism of global climate warming。 Since then, a series of related policies create a global carbon market and new institutional mechanisms, laying the foundation for future work. In 2007 December
Bali conference has formulated the "Bali road map", to reach a new agreement to cut emissions regulations in 2009, stressed the need to uphold the principles of the Convention and the protocol. In 2009 December, the fifteenth meeting of the parties to the UN Framework Convention on Climate Change was held in the Danish capital of Copenhagen.192 countries attended the follow-up project to discuss the "Kyoto Protocol" after the expiration of a commitment. However, the mitigation of climate warming is a real decision problem, which relates to fairness and efficiency of the global allocation of public resources. Any decision is likely to have a profound impact on economic development.

Therefore, governments are facing with the dilemma of how to coordinate the short-term economic development and environmental protection in the process of doing any decision. In order not to damage their own development, all governments are eager to hope other countries will hold the reduction burdens. This makes the international climate negotiations full of twists, turns and difficulties.

In the process of discussing the responsibilities and obligations of slowing down global warming, we should note that, due to the differences of the earth's greenhouse gas emissions, the differences in resource endowment and economic development level, obligations of the performance of emission reduction should be different.

So, as the Therefore, world's only legally binding international instrument, "Kyoto Protocol" embodies the principle of "common but differentiated responsibilities". According to this principle, the developed countries which have completed the industrial revolution should take more historical responsibility responding to the global warming.

\section{The Position and Roles of China's Government in Addressing Global Warming}

\subsection{Position of China's Government in Addressing Global Warming}

The International Energy Agency (IEA) in 2009 November issued a "2009 world energy outlook", the relevant data shows, in 2007 the global CO2 emissions amounted to 288 tons, China accounted for $21 \%$, accounted for $19 \%$ of the United States. From the historical cumulative emissions, in one hundred years from 1904 to 2004, China's total emissions accounted for only $8 \%$ of the world. Global 
greenhouse gas emissions from developed countries accumulated $80 \%$. At present, China is in the process of industrialization and urbanization. The pressure of developing the economy and improving people's life is very heavy. China's energy structure relied mainly on coal. The efficiency of energy use is poor. Since the reform and opening up economic construction consumes large amounts of natural resources and emissions of a large number of $\mathrm{CO}_{2}$. However, we also should see, china is still in the low-end of the global economy industry chain. China's economic model is oriented by export. Emissions each year, about $20 \%$ is due to the production of export products. These goods are mostly consumed by developed countries. As a responsible developing country, China's government attaches great importance to climate warming, bear the "common but different responsibilities for global warming”. Therefore, China's government has launched a series of initiatives, and actively participated in international climate negotiations and cooperation. Therefore, China's government has been widely praised by the international community. In 2007 June China's government announced China's first "National Program” in addressing global warming. In 2008 October published "White Paper" on climate change policy and action, China's government set up the foreign work leading group on climate change. China's government invested a lot of money, for saving energy, improving energy efficiency, developing recycling economy, cleaning energy and protecting environment. China's government has introduced a large number of the incentive fiscal and tax policy, to improve energy efficiency standards, promote energy-saving products, develop public transport and energy saving and environmental protection car.

On the eve of the Copenhagen climate change conference, China's government announced to the world: by 2020 carbon dioxide emissions per unit of GDP than in 2005 decreased by 40-45\%. This indicator will be mandatory indicators into the national economic and social development long-term planning.

\subsection{Roles of China's Government in Addressing Global Warming}

The role of the government is that the government in the management of the whole social economic life should assume the responsibilities and functions. Global warming is a common problem facing China and even global development. Targets for reducing carbon emissions are very arduous and long-term. The achievement of this goal and environmental protection and economic interests of the organization are a paradox. In the process of reducing carbon emissions and addressing climate warming, China's government needs to further enhance the ability of service, to strengthen the rule of law, to strengthen the sense of responsibility, and to Improve work efficiency. China's government is actively play planning, guiding and participatory role, in order to control global warming.

\subsubsection{Planning Role}

This role refers to: Chin's government should formulate the national economic and social development strategy of short-term Imedium-term and long-term planning as soon as possible. China's government has put the low carbon economy into the national economic and social development planning, and constantly improved the supporting measures.

4.2.1.1 Encourage all levels of government organizations, enterprises to establish energy-saving, water-saving and comprehensive utilization of resources management system. Mainly include: knock out backward equipment, take measures to reduce resource waste, improve and perfect the process design, improve resource utilization, use of advanced technology, to strengthen the "three wastes " utilization and processing and promote environmental protection. For the administrative institutions and enterprise energy saving management system put forward the improvement suggestions.

4.2.1.2 The combination of capital and goods, realize the organic combination of the stock of assets and budget. Mainly include: to strengthen the centralized management, unified adjust idle resources, guarantee the sharing of resources and reduce the repeated construction waste caused by loss of.

4.2.1.3 Develop resource consumption standards and quotas

Mainly include: formulate consumption standard of water, electricity, gas (warm), oil, coal and other kinds of resource ;amendment conference, reception, office consumption quota and quota, develop all kinds of facilities construction standards, assessment and reward and punishment system, organize regular inspection responsibilities.

\subsubsection{Guiding Role}

China's government has always attached great importance to environmental and climate change education and publicity, and efforts to raise public awareness. China's government clearly put forward in "China at the beginning of twenty-first Century" in the program of 
action for sustainable development: to develop actively all kinds of education, improve the awareness of sustainable development, development human resources, improve public participation in sustainable development of the scientific and cultural quality.

4.2.2.1 Playing the guiding role of government agencies

Cooperate with xinhuanet.com, people.com.cn and other large site, which is further enrich the "government agencies energy saving emission reduction" webpage columns and content, timely publicity of government organs to emission reduction situation. Through the promotion of the typical, collect, publish the government energy-saving emission reduction advice and suggestions, to expand the propaganda and the audience, play the exemplary role of government demonstration.

\subsubsection{Studying and Reporting}

In recent years, China actively research and advocacy on climate change, to carry out lectures and report on climate change .For example, held a number of central and provincial decision-makers climate change training classes, held a " climate change and ecological environment " seminars, opened a Chinese information network of climate change (in Chinese and English bilingual website). These actions have achieved good results.

4.2.2.3 Carrying out science and technology activities and publicity activities Carry out the "begin from me, start from every day, from the periphery to start, from the start bit by bit" as the theme and propaganda work, make energy-saving emission reduction into every citizen.

Through the national and local print media, television media and network media, phased, focused, step by step to intensify propaganda. In the organs, enterprises and institutions, schools and the community to carry out regular energy-saving environmental protection knowledge propaganda, held in energy-saving emission reduction awareness week and advocacy activities

4.2.3 Participatory role

Government is the model of social behavior and public morality and benchmarking. Government is one of the main energy-saving emission reduction organizations. From the position to start, start from their own, bit by bit from the start, the government should actively participate in energy-saving emission reduction activities. Actions can influence public opinion.

4.2.3.1 To develop "government energysaving emission reduction Convention", a clear energy emission reduction departments responsibilities and obligations, to implement the goals, responsibilities and measures. Make the government energy conservation and emissions reduction convention, is clear about the department of energy saving and emission reduction, carry out the duties and obligations target, responsibility and measures.

4.2.3.2 The staff in the performance of their functions and daily work process, adhere to conservation and self examination. Through the comparison of the standard limit provisions, find the gap. The staff should improve resource awareness, conservation awareness and sense of responsibility, to save resources and protect environment concept and requirements to the work, and strive to improve the work efficiency.

4.2.3.3 The establishment of energy reporting system

Administrative agency should publish authority energy consumption and expenditures regularly.

To energy-saving emission reduction as the theme, to create "energy-saving environmental protection office", saving electricity, saving oil, saving gas, water saving, make full use of renewable energy. In the administrative agencies actively promote the paperless office and the habit of saving resources.

4.2.3.4 To expand the use of resource recycling

Staff in the use of environmental protection pencil, recycled paper and other energy-saving environmental protection office supplies. Reuse of the waste computer, printer, battery, lamp and other office supplies recycling.

\section{Conclusions}

According to the composition of industrial structure and energy consumption structure and the actual situation, at present our country has not absolute commitment to reduce carbon emissions. China can only implement emission reduction from reducing carbon intensity per unit of GDP. But in the long run, we will inevitably have to directly face the absolute emission reduction problem, and will be further integrated into the global tide of low carbon economy.

\section{References}

[1] IPCC. Summary for Policymakers of the Synthesis Report of the IPCC Fourth Assessment Report. Cambridge. UK: Cambridge University Press. 2007. 
[2] IPCC. Summary for Policymakers of the Synthesis Report of the IPCC Third Assessment Report. Cambridge UK: Cambridge University Press. 2001.

[3] Xu Zairong. Global environmental issues and international response[M]. Beijing: China environmental press. 2007. 